\title{
Trait-based responses to cessation of nutrient enrichment in a tundra plant community
}

\author{
Chhaya M. Werner ${ }^{1,2,3} \cdot$ Maria Tuomi $^{4} \cdot$ Anu Eskelinen $^{1,2,3}$
}

Received: 2 December 2020 / Accepted: 17 October 2021 / Published online: 29 October 2021

(c) The Author(s) 2021

\begin{abstract}
Plant communities worldwide show varied responses to nutrient enrichment—including shifts in species identity, decreased diversity, and changes in functional trait composition - but the factors determining community recovery after the cessation of nutrient addition remain uncertain. We manipulated nutrient levels in a tundra community for 6 years of nutrient addition followed by 8 years of recovery. We examined how community recovery was mediated by traits related to plant resource-use strategy and plant ability to modify their environment. Overall, we observed persistent effects of fertilization on plant communities. We found that plants with fast-growing traits, including higher specific leaf area, taller stature and lower foliar C:N, were more likely to show a persistent increase in fertilized plots than control plots, maintaining significantly higher cover in fertilized plots 8 years after cessation of fertilization. Additionally, although graminoids responded most strongly to the initial fertilization treatment, forb species were more vulnerable to fertilization effects in the long-term, showing persistent decline and no recovery in 8 years. Finally, these persistent fertilization effects were accompanied by modified environmental conditions, including persistent increases in litter depth and soil phosphorous and lower soil C:N. Our results demonstrate the potential for lasting effects of nutrient enrichment in nutrient-limited systems and identify species traits related to rapid growth and nutrient-use efficiency as the main predictors of the persistence of nutrient enrichment effects. These findings highlight the usefulness of trait-based approach for understanding the persistent feedbacks of nutrient enrichment, plant dynamics, and niche construction via litter and nutrient build-up.
\end{abstract}

Keywords Nutrient addition $\cdot$ Recovery $\cdot$ Tundra $\cdot$ Functional traits $\cdot$ Litter

\section{Introduction}

Nutrient enrichment has been implicated as a driver of biodiversity loss and compositional change for plant communities globally (Bobbink et al. 2010; Harpole et al. 2016; Payne et al. 2017). As the negative impacts of nutrient enrichment

Communicated by Sarah M Emery.

Chhaya M. Werner

cwerner@ucdavis.edu

1 Department of Physiological Diversity, Helmholtz Center for Environmental Research (UFZ), 04318 Leipzig, Germany

2 German Centre for Integrative Biodiversity Research (iDiv) Halle-Jena-Leipzig, 04103 Leipzig, Germany

3 Department of Ecology and Genetics, University of Oulu, 90014 Oulu, Finland

4 Department of Arctic and Marine Biology, UiT, The Arctic University of Norway, 9019 Tromso, Norway on biodiversity have become clear, suggestions for ways to decrease nutrient inputs on natural systems have gained traction, including the abandonment of agriculture (Bakker and Berendse 1999), international management plans to reduce nutrient loads (Nielsen et al. 2019), or active restoration through top-soil removal and liming (Smolders et al. 2008). Despite these efforts, patterns of recovery after the cessation of nutrient enrichment have thus far been less well studied. In some cases, soil nutrients can recover relatively quickly to pre-enrichment levels (Stevens 2016), while the effects on plant communities in experimental studies often last even decades after treatments ceased, sometimes but not always including depressed species richness (Strengbom et al. 2001; Isbell et al. 2013; Street et al. 2015; Stevens 2016). Further investigating which mechanisms lead to either recovery or persistent changes after cessation of nutrient enrichment are needed to improve our understanding of community processes following global change pressures. 
Theoretical predictions and field data indicate that in nutrient-enriched conditions, traits that allow plants to take advantage of increased resources are those associated with higher competitive ability for light in resource-rich conditions by promoting fast growth (Reich 2014). These "resource-acquisitive" traits include high relative growth rate, high specific leaf area, high leaf $\mathrm{N}$ and $\mathrm{P}$ concentrations (Westoby et al. 2003; Adler et al. 2013; Reich 2014), and taller stature, which is associated with higher competitive ability for light (Fargione and Tilman 2002; Hautier et al. 2009). In contrast, species with the opposite, "resource conservative" traits that permit survival and growth under nutrient-constrained conditions are less likely to be able to take advantage of increased nutrient availability (Chapin et al. 1986; Fargione and Tilman 2002; Adler et al. 2013), and can exhibit greater loss-likelihood in resource-rich conditions (Stevens et al. 2011; Helsen et al. 2014; Kidd et al. 2017; Kaarlejärvi et al. 2017). Consequently, trait-driven species responses to nutrient addition can lead to shifts in functional trait composition, decreased species richness, and ultimately altered ecosystem functioning (Suding et al. 2008; Cadotte et al. 2011).

The potential role of traits in the recovery or persistent responses of species and communities after nutrient enrichment remains to be explored. On one hand, since species with resource-acquisitive traits are often most responsive to nutrient limitation (Chapin et al. 1986), they could be outcompeted by resource-conservative species once nutrient levels were no longer artificially elevated (Tilman 1988). However, if resource-acquisitive species modify their environment via niche construction, the abundance of these species may change the physical and chemical conditions of their environment in a way that promotes their dominance even after the cessation of nutrient enrichment (Laland et al. 2016). Niche construction can result in an environment where light is the most limiting resource, for which they are often dominant competitors (Hautier et al. 2009; Reich 2014; Borer et al. 2014). Resource-acquisitive species are likely to produce more litter due to higher turnover of leaves (Adler et al. 2013), which can reinforce community changes via a physical barrier to seed germination or light reduction (Lamb 2008). The litter produced by fast-growing species is also often rich in nitrogen and decomposes faster (Cornwell et al. 2008), which could maintain nutrient-rich conditions that benefit these same fast-growing, nutrient-demanding species. Despite the great potential of traits for predicting various community processes, their role as predictors of species' persistence in previously nutrient-enriched conditions has yet to be addressed.

Here we present results from a long-term study on the patterns and drivers of persistent consequences of nutrient enrichment for plant communities. This study in tundra experimentally manipulated nutrient availability with 6 years of nutrient addition, crossed factorially with habitat type, and reported trait-dependent changes in diversity and productivity (Eskelinen et al. 2012). We then examined whether the effects of nutrient enrichment persisted 8 years after the cessation of the nutrient addition treatment by comparing the pretreatment communities to communities 14 years after the experiment was established (i.e. showed persistent responses) or whether the communities had returned to the pretreatment stage (i.e. had recovered). Furthermore, we assessed whether species' persistence in previously nutrient-enriched conditions was explained by traits. Tundra ecosystems are ideal to test theories of persistent nutrient effects, with strong resource limitation, and high diversity of species in small plots (Shaver and Chapin 1980; Virtanen et al. 2013). These communities have few to no exotic species, which allows tests of the general effects of nutrient enrichment on native communities (separate from feedbacks between invasive species and nutrient enrichment). Finally, the interspersion of two different habitat types with greatly varying initial nutrient levels at our study site (Eskelinen et al. 2009) facilitates investigation of the generalizability of patterns and mechanisms.

We hypothezed that the previously fertilized plots would have persistently lower species richness (H1a), higher turnover of species from the pre-nutrient addition community (H1b) and larger shifts in functional groups (H1c) than control plots. We predicted that species with resource-acquisitive traits (i.e., greater SLA, height and N concentrations) would be more likely to have persistent increases in the enriched plots than those with resource conservative traits $(\mathrm{H} 2)$. We also predicted that this trait-based increase would be associated with aspects of niche construction, including increased accumulation of litter (H3a) and persistent differences in soil nutrients (H3b).

\section{Methods}

\section{Study system}

This study was conducted in tundra communities above treeline on Mount Saana, located in northwest Finland $\left(69.05^{\prime} \mathrm{N}, 20.83^{\prime} \mathrm{E}\right)$. Treeline lies in $600-650 \mathrm{~m}$ a.s.l. On Mt. Saana, two distinct bedrock types result in a mosaic pattern of soil and vegetation (hereafter referred to as "habitat types"). Non-acidic and relatively nutrient-rich soils, derived from dolomitic bedrock, support forb- and graminoid-rich Dryas heaths ("fertile habitat"). In contrast, acidic and relatively nutrient-poor soils lie above siliceous rocks, and support dwarf shrub- and graminoid-rich Empetrum heaths ("infertile habitat"). Fertile habitats had higher soil $\mathrm{pH}$ and $\mathrm{NH}_{4}-\mathrm{N}$ than infertile habitats (Eskelinen et al. 2009). For our experimental study, we chose five patches for each of 
these two habitat types, fertile and infertile habitats, spatially interspersed within a distance of $5 \mathrm{~km}$, at altitudes of 720-800 m a.s.l. and with similar topographic and moisture conditions.

\section{Experimental design}

In 2004 , we established eight $25 \times 25 \mathrm{~cm}$ plots at each of the ten sites (five fertile and five infertile habitats), for a total of 80 plots. To examine the persistent effects of nutrient enrichment on plant communities, we established a fully factorial combination of three treatments: fertilization, liming, and grazer exclusion. Each site had one replicate of each of the consequent treatment combinations. Our original experimental design included liming and grazer exclusion to make sure that lower $\mathrm{pH}$ at some sites would not constrain plants from responding to fertilization and because recovery from fertilization could depend on grazing (Olsen and Klanderud 2014).

Fertilization was conducted with a fast-dissolving NPK 16-9-22 fertilizer, which we applied twice per growing season (in mid-June and at the end of July) every year from 2005 to 2010. Fertilizer was applied in the plot and an additional $15 \mathrm{~cm}$ wide buffer on each side. Total nutrient quantities per year were $9.6 \mathrm{~g} \mathrm{~N} / \mathrm{m}^{2}, 5.4 \mathrm{~g} \mathrm{P} / \mathrm{m}^{2}$, and $13.2 \mathrm{~g} \mathrm{~K} / \mathrm{m}^{2}$. Fertilizer applications were followed immediately by watering using $500 \mathrm{~mL}$ of water per plot from nearby brooks. Liming to manipulate $\mathrm{pH}$ was conducted on the same schedule and with the same spatial buffer as fertilization. We added $300 \mathrm{~g} / \mathrm{m}^{2}$ of dolomite lime $\left(\mathrm{CaMg}\left(\mathrm{CO}_{3}\right)_{2}\right)$ to the plots in 2005 and $600 \mathrm{~g} / \mathrm{m}^{2}$ in each of 2006-2010. Grazer exclosures were established in August 2004 and constructed of galvanized mesh netting approximately $1.5 \mathrm{~m}$ in circular diameter (mesh size $1.2 \times 1.2 \mathrm{~cm}$ ). The exclosures were $80-100 \mathrm{~cm}$ above ground and $10 \mathrm{~cm}$ deep into the soil to prevent grazing by both semi-domesticated reindeer (the dominant grazer in the system), voles and lemmings. Fertilization and liming treatments were terminated after 2010, but grazer exclosures were left in place throughout the duration of the study.

We initially included liming treatment as a predictor variable in our models, but since it was not a significant component to any of the initial treatment effects (Eskelinen et al. 2012) or in any of our analyses, we pooled across the limed and un-limed plots and will not discuss this treatment further. Furthermore, reindeer grazing in the system was high from the start of the experiment until around 2012; however, due to changed reindeer herding practices and following shifts in the movement of the herds in Kilpisjärvi area, grazing pressure on Mt. Saana was considerably lower from 2013 to 2019. For this reason, grazing pressure after the termination of fertilization is not fully comparable to years 2004-2010. We included grazing in our statistical models as it did affect some variables; however, due to changed reindeer herding practices our results probably greatly underestimate the potential impact of grazing on recovery from fertilization and is therefore given less consideration.

\section{Community measurements}

The presence and percent cover of all vascular species in the $25 \times 25 \mathrm{~cm}$ plots was estimated during the peak biomass of vegetation in late July-August of 2004 (just before application of experimental treatments), 2010 (at the end of fertilization and liming treatments), and 2019. In 2004 and 2019 cover was estimated visually by an experienced person, and in 2010 cover estimates were conducted using a point-intercept method (Jonasson 1988) with 40 evenly spaced sampling points per $25 \times 25 \mathrm{~cm}$ plot. Although we included the 2010 data as useful reference information for initial treatment effects, our questions and findings focus predominantly on the changes from 2004 to 2019 (persistent effects of treatments) when the same method was used. For four species pairs that were difficult to tell apart in their vegetative state, we pooled the cover estimates (Carex bigelowii and $C$. vaginata, Equisetum arvense and E. pratense, Equisetum scirpoides and E. varigetum, Anthoxantum odoratum and Poa alpigena).

In 2019 we additionally measured litter depth at three uniformly assigned points per plot, and sampled soil at three points in the $15 \mathrm{~cm}$ fertilized buffer zone surrounding each plot. Soils were later analyzed for total $\mathrm{N}$ and $\mathrm{C}$ (used to calculate $\mathrm{C}: \mathrm{N}$ ratio), $\mathrm{NH}_{4}, \mathrm{P}, \mathrm{K}, \mathrm{Ca}$, and $\mathrm{Mg}$ concentrations (Eurofins lab, Oulu).

\section{Trait measurements}

To investigate the role of plant traits in species' responses to fertilization, we measured three traits: specific leaf area (SLA, leaf area $\left[\mathrm{mm}^{2}\right]$ per unit of dry leaf mass [mg]), foliar $\mathrm{C}: \mathrm{N}$ ratio (based on the percentage of plant total carbon and nitrogen in plant leaves), and height ( $\mathrm{mm})$. Trait data were collected for 38 species in 2011 from the area where the experiment was carried out, with $>10$ individuals collected for each species, following standard collection and handling protocols (Cornelissen et al. 2003). We additionally used trait data from a study located in a nearby area for six species (Anthoxantum odoratum and Poa alpigena [pooled as above], Pyrola minor, Ranunculus acris, Gentiana nivalis, and Solidago virguarea) which were collected in 2014 (Kaarlejärvi et al. 2017). SLA was analyzed using ImageJ to calculate fresh leaf area (Rasband 1997). Total C and N of leaves were analyzed on a CHN Element Analyzer (Fisons Instruments, Milan, Italy). 


\section{Data analysis}

Analyses were carried out using linear mixed-effects models (LME) using a model selection approach. The full models included habitat type, fertilization, herbivory, and their interactions as explanatory variables, and site as a random variable. We assessed differences in multiple vegetation metrics, considering both initial differences (comparing 2004 and 2010 data) and persistent differences (comparing 2004 and 2019 data). This structure was used to investigate initial and persistent differences on the plot level in species richness (H1a), species turnover (H1b, calculated as 1 - Jaccard similarity), and changes in total graminoid, forb, fern, and shrub cover $(\mathrm{H} 1 \mathrm{c}$, only comparing 2004-2019). Since 2010 cover data was measured using a different method than 2004 and 2019 cover data, we did not compare it directly to the other years, but did model differences between treatments in 2010 functional group cover to demonstrate initial treatment effects (Supplement S3). We did not have pre-treatment data for moss and lichen cover, so we modeled this using the 2019 measurements only rather than a change between years (H1c). We also modeled litter depth (H3a) and soil nutrients (H3b) measured in 2019 as response variables. Model selection was conducted using comparisons of AICc values to select the best-fit model from all possible combinations, AICc values and $\triangle \mathrm{AICc}$ comparisons are reported in Supplemental Table S1. Results are reported as effect sizes \pm standard error.

To investigate plant traits as predictors of individual species' responses to fertilization (H2), we took the difference in species' percent cover between 2004 and 2019 and simplified this to a binary representation of change, either increasing or not increasing. We modeled this response using generalized linear mixed-effects models (GLMM) with a binomial structure, with a separate model for each trait (height, SLA, and $\mathrm{C}: \mathrm{N})$. The response variable was the probability for each species to increase in each plot, and the predictors were the traits (trait values were centered and scaled), habitat type, fertilization, herbivory, and their interactions (including three- and four-way interactions) as fixed factors and a site as a random variable. We used the same AICc model selection approach described in the previous paragraph. Using this GLMM structure allowed us to consider species that were lost from or colonized each plot relative to the local species pool. To ensure that we were focusing on species that were or could be present in plots, rather than those that are completely absent from a given site, only species that were present in the site at any of the three-time points were included in the analysis. As a robustness check, we also included a LME model of change in cover for the species present in the plot, the results of which were generally consistent and are included in Supplemental Table S2.
All data management and analyses were conducted in $\mathrm{R}$ and used 'simba', 'plyr', and 'tidyverse' packages (Wickham 2011, 2017; Jurasinski and Retzer 2012; R Core Team 2019). All models were fit using the 'Ime4' package, and model selection was conducted using the 'MuMIn' package (Bates et al. 2015; Barton 2019). Plots of the fitted relationship between traits and probability of increase were generated using the glm.predict() function, which uses the delta method approximation for standard error estimates. Figures were made using 'ggplot2' and 'cowplot' packages (Wickham 2016; Wilke 2019).

\section{Results}

\section{H1: community change}

Species richness initially increased more in fertilized plots than in unfertilized plots (i.e., comparing 2004-2010, Table $1 ; 1.3 \pm 0.48$ ), but showed no persistent effects of fertilization (i.e., comparing 2004-2019, Supplemental Fig. S1) despite an overall decrease in species richness across all treatments (from $9.9 \pm 0.32$ species per plot in 2004 to $8.1 \pm 0.23$ in 2019). We did find both initial and persistent effects of fertilization on species turnover (Fig. 1). Initial turnover between 2004 and 2010 was higher in fertilized plots than unfertilized plots across all treatments and habitats $(0.15 \pm 0.02)$. Herbivore presence mitigated the initial effects of fertilization on turnover but did not completely counteract it (Supplemental Fig. S2; $-0.078 \pm 0.03$ ). Persistent species turnover between 2004 and 2019 was also higher in fertilized plots than unfertilized plots $(0.086 \pm 0.03)$. There was no persistent interaction between fertilization and herbivory treatments.

Although graminoid cover had a strong initial response to fertilization, with an average cover in 2010 of $74 \%$ in fertilized plots, compared to $27 \%$ in unfertilized plots (Supplement Fig. S3; $34 \pm 5.5$ ), there was no persistent difference of fertilization on graminoid cover, with 2019 graminoid cover averaging $14 \%$ in fertilized plots and $10 \%$ in unfertilized plots (Fig. 2a). (Note that these cover values are comparable within but not between years due to different methods of measuring cover in 2010 versus 2004 and 2019, see methods for details). In contrast, forb cover showed minimal initial response to fertilization, with an average cover in 2010 of $26 \%$ in fertilized plots and 23\% in unfertilized plots (Supplement Fig. S3; $4.1 \pm 2.6$ ). However, we did observe persistent negative effects of fertilization on forb cover in fertile habitat (Fig. 2b, $19 \%$ versus $49 \%$ ) but not infertile habitat (19\% versus $18 \%$; Table 1 ; habitat $\times$ fertilization $39 \pm 9.0$ ). There was an additional interaction between herbivory and habitat on persistent differences in forb cover $(-17 \pm 9.0)$, but this did not interact with the fertilization treatment. Shrub cover 
Table 1 Effects of fertilizer, herbivory, habitat, and their interactions on richness change, community turnover (1—Jaccard similarity), change in graminoid cover, change in forb cover, 2019 moss and lichen cover, and 2019 litter depth

\begin{tabular}{|c|c|c|c|c|c|c|c|}
\hline & Intercept & Fertilized & Herbivory & Habitat & Fertilized $*$ herbivory & Fertilized $*$ habitat & Herbivory* habitat \\
\hline \multicolumn{8}{|c|}{ Richness change } \\
\hline Initial & $0.97 \pm 0.41$ & $1.3 \pm 0.48$ & - & $-0.75 \pm 0.48$ & - & - & - \\
\hline Persistent & $-2.8 \pm 0.54$ & - & $0.72 \pm 0.44$ & $1.3 \pm 0.70$ & - & - & - \\
\hline \multicolumn{8}{|c|}{ Species turnover (Jaccard) } \\
\hline Initial & $0.59 \pm 0.02$ & $0.15 \pm 0.02$ & $0.045 \pm 0.02$ & $-0.045 \pm 0.02$ & $-0.078 \pm 0.03$ & - & - \\
\hline Persistent & $0.66 \pm 0.03$ & $0.086 \pm 0.03$ & - & $-0.19 \pm 0.03$ & - & - & - \\
\hline \multicolumn{8}{|c|}{ Graminoid change } \\
\hline Persistent & $-11.8 \pm 3.4$ & - & $10.7 \pm 3.7$ & $11.1 \pm 4.9$ & - & - & $-8.1 \pm 5.2$ \\
\hline \multicolumn{8}{|l|}{ Forb change } \\
\hline Persistent & $-11.6 \pm 6.4$ & $-40.8 \pm 6.4$ & $18.8 \pm 6.4$ & $15.9 \pm 9.0$ & - & $39.2 \pm 9.0$ & $-17.4 \pm 9.0$ \\
\hline \multicolumn{8}{|l|}{ Moss cover } \\
\hline 2019 & $9.4 \pm 1.6$ & $-5.0 \pm 1.8$ & - & $-3.7 \pm 1.8$ & - & - & - \\
\hline \multicolumn{8}{|l|}{ Litter depth } \\
\hline 2019 & $2.2 \pm 0.37$ & $2.0 \pm 0.46$ & $-1.8 \pm 0.46$ & $0.76 \pm 0.33$ & $-1.6 \pm 0.66$ & - & - \\
\hline
\end{tabular}

Values are effect size \pm standard error, '-' indicates that the variable was not included in the best model

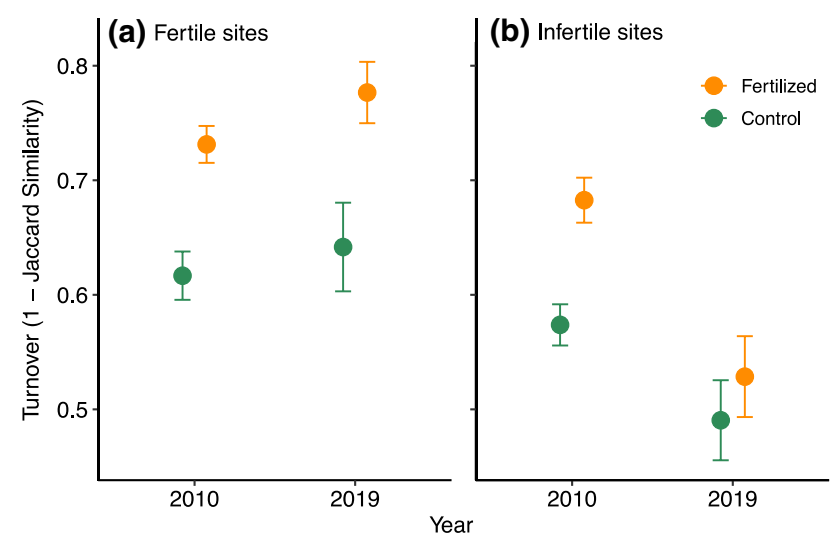

Fig. 1 Species turnover compared to 2004 pre-treatment data, in a fertile and $\mathbf{b}$ infertile sites. Turnover is measured as 1-Jaccard similarity (using presence/absence data) between time points for each plot $($ mean $\pm \mathrm{SE})$. Color indicates fertilization treatment

did not change in response to fertilization (Fig. 2c, Supplemental Fig. S5). Species-level changes are presented in Supplemental Table S3. Moss and lichen cover (measured only in 2019) was lower in fertilized plots than unfertilized plots (2.5\% versus $7.6 \%$; Supplemental Fig. S4).

\section{H2: traits as predictors of species responses}

We found that functional traits interacted with fertilization to explain the probability of species increasing in cover from 2004 to 2019, i.e., persistent responses (Table 2). Tallstatured species were less likely to increase overall, but more likely to increase in fertilized plots than control plots (Fig. 3, trait $\times$ fertilized effect size $0.27 \pm 0.15$ ). Species with

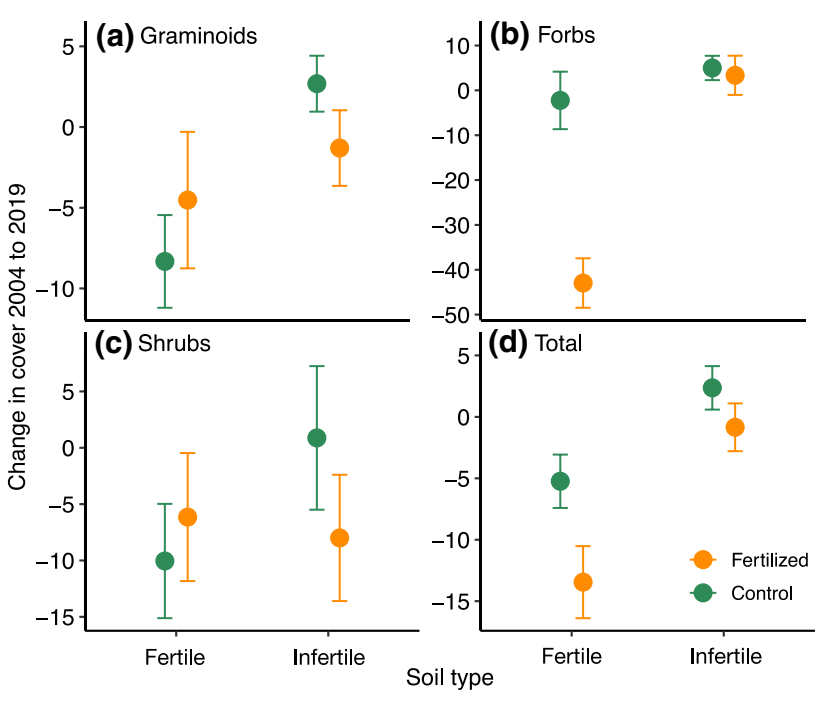

Fig. 2 Change in cover from 2004 to 2019 of a-c different functional groups and $\mathbf{d}$ total cover, by soil type. Values are displayed as mean \pm SE. Total cover also includes Equisetum species, which are not included in any of the three main functional groups

low SLA were mostly likely to increase in control plots, while in fertilized plots species with high SLA were equally likely to increase as species with low SLA (trait $\times$ fertilized $0.39 \pm 0.14)$. Species with a high $\mathrm{C}: \mathrm{N}$ ratio-i.e., species having low $\mathrm{N}$ concentrations-were most likely to increase in control plots, while in fertilized plots species with low and high C:N ratio were equally likely to increase (Fig. 1c; trait $\times$ fertilized $-0.27 \pm 0.12$ ). 

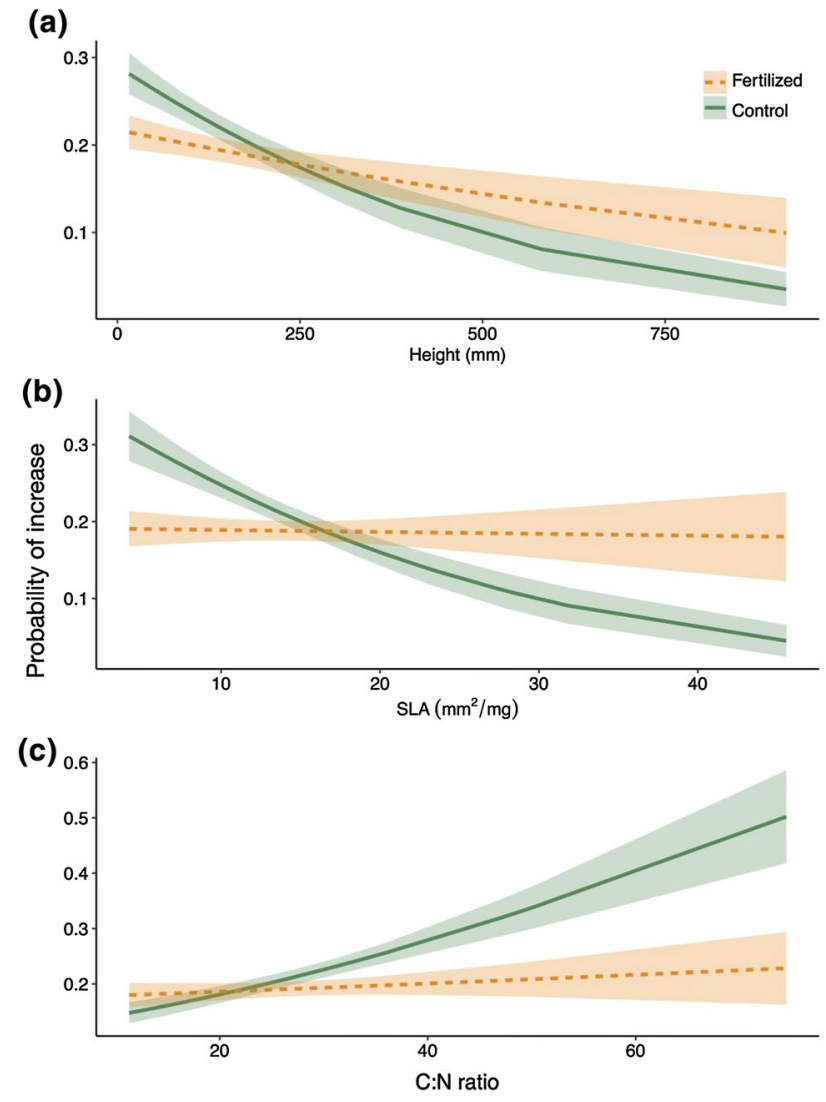

Fig. 3 Relationship between species' traits and their probability to increase in cover between 2004 and 2019 by fertilization treatment. Traits include a plant height $\mathbf{b}$ specific leaf area $\mathbf{c}$ leaf C:N. Values are displayed as fitted relationship with estimated standard errors, generated using the 'glm.predict' function for these models

These relationships between traits and fertilization were consistent within habitats as well as across habitats (Supplemental Fig. S5), although the overall relationships between height or SLA and probability of increasing differed somewhat between habitat types, with a stronger advantage to tallstatured and high SLA species in-fertile sites (Supplemental Fig. S5; height trait $\times$ habitat $-0.29 \pm 0.14$; SLA trait $\times$ habitat $-0.26 \pm 0.14$ ). Although the grazer exclusion treatment had an overall effect on species' probability to increase (all trait models $0.17 \pm 0.11$ ), this did not differ between fertilization treatments or interact with species traits.

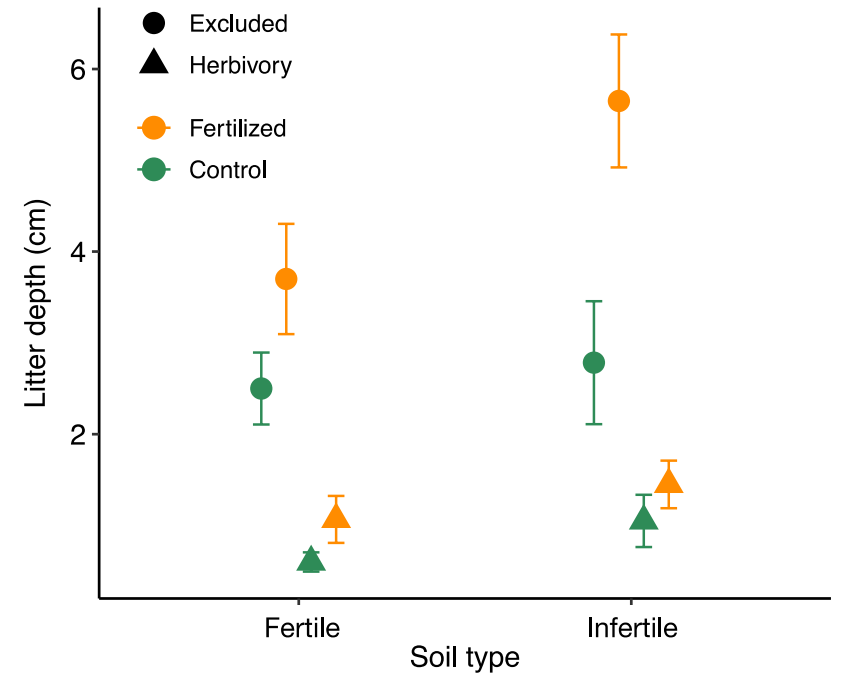

Fig. 4 Litter depth by fertilization treatment and herbivory treatment, in fertile and infertile sites (mean $\pm \mathrm{SE}$ ). Litter depth was higher in fertilized and ungrazed plots

\section{H3: litter depth and soil nutrients}

Litter depth was higher in fertilized plots $(3.0 \mathrm{~mm}$ versus $1.7 \mathrm{~mm}$; Fig. $4 ; 2.0 \pm 0.46)$ and ungrazed plots $(3.7 \mathrm{~mm}$ versus $1.0 \mathrm{~mm} ; 1.8 \pm 0.46)$ as well as infertile habitats $(2.7 \mathrm{~mm}$ versus $2.0 \mathrm{~mm} ; 0.76 \pm 0.33$ ). There was an additional interaction between fertilization and herbivory, with a larger effect of fertilization on litter depth in plots where herbivores were excluded than those where they were present $(-1.6 \pm 0.66)$.

Soil phosphorus $(\mathrm{P})$ concentration and soil $\mathrm{C}: \mathrm{N}$ ratio indicated some persistent below-ground effects of fertilization, although no other nutrients differed by fertilization treatment (Supplemental Fig. S6). P was higher in fertilized plots than unfertilized plots (1200 ppm versus $1000 \mathrm{ppm}$; effect size $176 \pm 44)$. C:N ratio differed strongly between habitat types (17 versus $22 ; 4.7 \pm 1.2$ ) but was marginally lower in fertilized plots across habitat types (19 versus $20 ;-0.75 \pm 0.37$ ). Total nitrogen, ammonia, nitrate, potassium, calcium, and magnesium all showed no persistent effects of fertilization.

Table 2 Effect of fertilizer, herbivory, habitat, traits (height, specific leaf area, and foliar C:N) and their interactions on the probability of species increase between 2004 and 2019

\begin{tabular}{|c|c|c|c|c|c|c|c|}
\hline & Intercept & Trait & Fertilized & Herbivory & Habitat & Trait $*$ fertilized & Trait* habitat \\
\hline Height & $-1.4 \pm 0.11$ & $-0.30 \pm 0.13$ & $-0.13 \pm 0.11$ & $0.17 \pm 0.11$ & $0.30 \pm 0.11$ & $0.27 \pm 0.15$ & $-0.29 \pm 0.14$ \\
\hline SLA & $-1.5 \pm 0.11$ & $-0.28 \pm 0.12$ & $-0.07 \pm 0.11$ & $0.17 \pm 0.11$ & $0.20 \pm 0.11$ & $0.39 \pm 0.14$ & $-0.26 \pm 0.14$ \\
\hline $\mathrm{C}: \mathrm{N}$ & $-1.4 \pm 0.11$ & $0.31 \pm 0.08$ & $-0.13 \pm 0.11$ & $0.17 \pm 0.11$ & $0.23 \pm 0.11$ & $-0.27 \pm 0.12$ & - \\
\hline
\end{tabular}

Values are effect size \pm standard error, '-' indicates that the variable was not included in the best model 


\section{Discussion}

Adding to the growing evidence that plant communities are slow to recover after nutrient addition (Strengbom et al. 2001; Isbell et al. 2013; Street et al. 2015; Stevens 2016), we found persistent differences in fertilized plant communities over 8 years after the end of the nutrient treatment. While several other studies have identified individual species or groups that showed lasting responses to fertilization (Olsen and Klanderud 2014; Street et al. 2015), ours is among the first to successfully use functional traits as predictors of these persistent changes. Furthermore, these changes were associated with persistent litter build-up and enhanced soil nutrients. These results support the predictions of niche construction theory (Thakur and Wright 2017), that species can promote their own abundance by modifying the environmental filters present in the local area (Laland et al. 2016), and provide evidence that this species-engineered microenvironment has strong consequences for the trait distribution of species in the community.

We found that species with traits associated with resource acquisitiveness (tall stature, high SLA, and low foliar C:N) were more likely to have persistent increases in fertilized plots than control plots. Similar suites of traits have previously been associated with species most likely to respond to nutrient addition (Suding et al. 2005; La Pierre and Smith 2015), but the role of traits in recovery and persistent changes has been less clear. Our findings indicate that species with resource-acquisitive traits may modify their environment to benefit their own success in ways that hamper community recovery to the pre-nutrient-enriched state. We found higher litter quantity in previously fertilized plots (up to twice as deep as the control plots) 9 years after the cessation of fertilization. Deep litter layers can inhibit germination (Kitajima and Tilman 1996; Henry et al. 2004; Lamb 2008), and reduce the immigration success of shorter-statured resource-conservative species, consequently maintaining the dominance of already established resource-acquisitive species. High SLA and low C:N, traits that in our data were associated with persistent responses to fertilization, are strongly linked to faster litter decomposition rates (Cornwell et al. 2008) which can combine with persistent microbial community changes to result in persistently elevated nutrient cycling rates (Carreiro et al. 2000; Power et al. 2006; Clark et al. 2009; Högberg et al. 2014; Gravuer and Eskelinen 2017; Bowman et al. 2018). Elevated nutrient cycling rates could in turn benefit resource-acquisitive plants that take advantage of resources as they become available (Suding et al. 2008), resulting in an overall fast-cycling system (Wardle et al. 2004; Eskelinen et al 2020). It is possible that such feedback mechanisms maintain the dominance of resource-acquisitive species in our system even 8 years after the cessation of nutrient enrichment. The reinforcement between above-ground traits and below-ground processes may represent alternative states created by nutrient enrichment; potentially transient states, but persistent on the scale of decades (Isbell et al. 2013; Chisholm et al. 2015).

In addition to trait-based changes, we observed persistent species turnover and changes in the total cover of different functional groups. During the initial period of nutrient enrichment, we observed elevated species richness and higher species turnover in fertilized plots. The effects on species richness did not persist after the cessation of nutrient addition, but the differences in species composition (higher turnover rates) did, indicating that the species recruiting into the fertilized plots after the end of the treatment were different than those that were lost. Deeper litter layer such as we observed in the previously fertilized plots could have particularly strong influence on forbs-the group that showed the largest persistent decline in our study. We observed a persistent drop in forb cover in-fertile habitats, with fertilized plots having an average of $19 \%$ forb cover compared to $49 \%$ in unfertilized plots. This difference is particularly striking because it was not apparent as a response to nutrient addition, but appeared as a lagged response to the nutrient enrichment 8 years after the treatments were terminated. In tundra communities, where strongly vegetatively reproducing shrubs and graminoids form a considerable proportion of species, seedling-based reproduction is often found for forbs (Welling and Fennici 2000; Austrheim and Eriksson 2003; Eskelinen et al. 2017). The deeper litter layer may have prevented the recruitment of forb seedlings after the cessation of nutrient addition. These litter layer impacts could also extend to bryophyte and lichen communities, suppressing their growth, as suggested by the approximately half lower total cover of bryophytes and lichens in control plots than in fertilized plots. We did find that graminoid cover returned to pre-treatment levels, which has been observed in some recovery experiments (Bowman et al. 2018) but not others (Olsen and Klanderud 2014; Street et al. 2015). Long-term plant community changes or direct effects of nutrients could also deplete belowground seed bank diversity, further reducing the potential for recovery (Bakker and Berendse 1999; Basto et al. 2015; Eskelinen et al. 2021, accepted).

The trait-based patterns we observed were generally consistent across the two habitat types we studied and across herbivory treatments. The interspersed tundra habitats differ not only in initial soil conditions but also in community composition, ranging from the dominance of very slow-growing evergreen dwarf shrubs in infertile heaths to N-rich forbs and legumes in fertile heaths (Eskelinen et al. 2009; Stark et al. 2012). Nevertheless, species' responses in both habitats were explained by their traits in a similar way. Persistent effects of nutrient addition may also be influenced by mowing or grazing regime, 
as previous studies have found that removal of standing biomass (including live plants and litter) can improve recovery trajectories (Olff and Bakker 1991; Olsen and Klanderud 2014; Storkey et al. 2015). We did not observe effects of reindeer exclusion on any aspects of recovery other than litter depth; however, this is likely due to altered herd management and related changes in grazing intensity at our study site (see "Methods"), a caveat that cautions against drawing strong conclusions about this factor in our study. Further, we suspect that these changes in herd management and grazing pressure, coupled with climate trends that are particularly strong in arctic ecosystems (Box et al. 2019) but see Virtanen et al. (2021), are responsible for the strong changes we observed over 15 years in our control plots. It is noteworthy that even relatively low grazing pressure can mitigate the persistent effects of nutrient enrichment on litter accumulation, with possible consequences for community resilience through germination and above-belowground interactions. These habitat- and grazing regime-independent results highlight the strength of our findings and point toward the potential of plant traits to be a useful generalizable currency for understanding persistent responses to nutrient enrichment.

Plant traits have been used as a generalizable currency for understanding existing differences between communities (McGill et al. 2006), and for forecasting species and community vulnerability and resistance to various global change factors, including climate warming, changes in rainfall, and nutrient enrichment (Kimball et al. 2016; Bjorkman et al. 2018; Harrison and LaForgia 2019). We propose that they also have the potential in understanding community recovery from such changes, niche construction mechanisms and patterns of resilience and regime shifts between alternative states. Our results highlight the usefulness of trait-based approaches for predicting persistent responses to nutrient enrichment, with implications on planning restoration strategies in human-degraded ecosystems.

Supplementary Information The online version contains supplementary material available at https://doi.org/10.1007/s00442-021-05064-w.

Acknowledgements We thank Risto Virtanen for comments on the manuscript and input on the experimental setup, Elina Kaarlejärvi for help collecting plant trait data, John Latson for his assistance in the field, and Nicolina Johanson, Johannes Niemi, and Femke Pijcke for help collecting soil samples. We are also grateful to Tuulikki Pakonen for analyzing foliar C:N ratios, and Kilpisjärvi Biological Station for providing accommodation and lab space.

Author contribution statement $\mathrm{AE}$ designed and established the initial experiment. AE, MT, and CMW collected field data. CMW conducted the analyses, and all authors contributed to the writing of the manuscript and approved the final submission.
Funding Open Access funding enabled and organized by Projekt DEAL. This study was funded by the Finnish Cultural Foundation and Academy of Finland (project numbers 253385 and 24302284) to A. Eskelinen.

Data availability We have archived our data in a permanent Figshare repository at https://doi.org/10.6084/m9.figshare.14959863.v1.

Code availability We have archived our code in a permanent Figshare repository at https://doi.org/10.6084/m9.figshare.14959863.v1.

\section{Declarations}

Conflict of interest The authors declare that they have no conflict of interest.

Research involving human participants and/or animals This article does not contain any studies with human participants or animals performed by any of the authors.

Consent to participate Not applicable.

Consent for publication Not applicable.

Open Access This article is licensed under a Creative Commons Attribution 4.0 International License, which permits use, sharing, adaptation, distribution and reproduction in any medium or format, as long as you give appropriate credit to the original author(s) and the source, provide a link to the Creative Commons licence, and indicate if changes were made. The images or other third party material in this article are included in the article's Creative Commons licence, unless indicated otherwise in a credit line to the material. If material is not included in the article's Creative Commons licence and your intended use is not permitted by statutory regulation or exceeds the permitted use, you will need to obtain permission directly from the copyright holder. To view a copy of this licence, visit http://creativecommons.org/licenses/by/4.0/.

\section{References}

Adler PB, Fajardo A, Kleinhesselink AR, Kraft NJB (2013) Trait-based tests of coexistence mechanisms. Ecol Lett 16:1294-1306. https:// doi.org/10.1111/ele.12157

Austrheim G, Eriksson O (2003) Recruitment and life-history traits of sparse plant species in subalpine grasslands. Can J Bot 81:171182. https://doi.org/10.1139/b03-010

Bakker JP, Berendse F (1999) Constraints in the restoration of ecological diversity in grassland and heathland communities. Trends Ecol Evol 14:63-68. https://doi.org/10.1016/S0169-5347(98)01544-4

Bartoń K (2019) MuMIn: multi-model inference. In: https://CRAN.Rproject.org/package $=$ cowplot. https://cran.r-project.org/web/packa ges/MuMIn/index.html. Accessed 27 Mar 2020

Basto S, Thompson K, Phoenix G, Sloan V, Leake J, Rees M (2015) Long-term nitrogen deposition depletes grassland seed banks. Nat Commun 6:1-6. https://doi.org/10.1038/ncomms7185

Bates D, Mächler M, Bolker B, Walker S (2015) Fitting linear mixedeffects models using lme4. J Stat Softw 67:1-48. https://doi.org/ 10.18637/jss.v067.i01

Bjorkman AD, Myers-Smith IH, Elmendorf SC, Normand S, Rüger N, Beck PSA et al (2018) Plant functional trait change across a 
warming tundra biome. Nature 325:1-62. https://doi.org/10.1038/ s41586-018-0563-7

Bobbink R, Hicks K, Galloway J, Spranger T, Alkemade R, Ashmore $M$ et al (2010) Global assessment of nitrogen deposition effects on terrestrial plant diversity: a synthesis. Ecol Appl 20:30-59. https://doi.org/10.1890/08-1140.1

Borer ET, Seabloom EW, Gruner DS, Harpole WS, Hillebrand H, Lind EM et al (2014) Herbivores and nutrients control grassland plant diversity via light limitation. Nature 508:517-520. https://doi.org/ 10.1038/nature13144

Bowman WD, Ayyad A, de Mesquita CPB, Fierer N, Potter TS, Sternagel S (2018) Limited ecosystem recovery from simulated chronic nitrogen deposition. Ecol Appl 28:1762-1772. https://doi. org/10.1002/eap. 1783

Box JE, Colgan WT, Christensen TR, Schmidt M, Lund M, Parmentier F-JW et al (2019) Key indicators of Arctic climate change: 1971-2017. Environ Res Lett 14:045010. https://doi.org/10.1088/ 1748-9326/aafc1b

Cadotte MW, Carscadden K, Mirotchnick N (2011) Beyond species: functional diversity and the maintenance of ecological processes and services. J Appl Ecol 48:1079-1087. https://doi.org/10.1111/j. 1365-2664.2011.02048.x

Carreiro MM, Sinsabaugh RL, Repert DA, Parkhurst DF (2000) Microbial enzyme shifts explain litter decay responses to simulated nitrogen deposition. Ecology 81:2359-2365. https://doi.org/10. 1890/0012-9658(2000)081[2359:MESELD]2.0.CO;2

Chapin FS III, Vitousek PM, Van Cleve K (1986) The nature of nutrient limitation in plant communities. Am Nat 127:48-58. https://doi. org/10.1086/284466

Chisholm RA, Menge DNL, Fung T, Williams NSG, Levin SA (2015) The potential for alternative stable states in nutrient-enriched invaded grasslands. Theor Ecol 8:399-417. https://doi.org/10. 1007/s12080-015-0258-8

Clark CM, Hobbie SE, Venterea R, Tilman D (2009) Long-lasting effects on nitrogen cycling 12 years after treatments cease despite minimal long-term nitrogen retention. Glob Change Biol 15:1755-1766. https://doi.org/10.1111/j.1365-2486.2008.01811.x

Cornelissen JHC, Lavorel S, Garnier E, Diaz S, Buchmann N, Gurvich DE (2003) A handbook of protocols for standardised and easy measurement of plant functional traits worldwide. Aust J Bot 51:335-380. https://doi.org/10.1071/bt02124

Cornwell WK, Cornelissen JHC, Amatangelo K, Dorrepaal E, Eviner VT, Godoy O et al (2008) Plant species traits are the predominant control on litter decomposition rates within biomes worldwide. Ecol Lett 11:1065-1071. https://doi.org/10.1111/j.1461-0248. 2008.01219.x

Eskelinen A, Stark S, Männistö M (2009) Links between plant community composition, soil organic matter quality and microbial communities in contrasting tundra habitats. Oecologia 161:113-123. https://doi.org/10.1007/s00442-009-1362-5

Eskelinen A, Harrison S, Tuomi M (2012) Plant traits mediate consumer and nutrient control on plant community productivity and diversity. Ecology 93:2705-2718. https://doi.org/10.1890/ 12-0393.1

Eskelinen A, Kaarlejärvi E, Olofsson J (2017) Herbivory and nutrient limitation protect warming tundra from lowland species' invasion and diversity loss. Glob Change Biol 23:245-255. https://doi.org/ 10.1111/gcb.13397

Eskelinen A, Gravuer K, Harpole WS, Harrison A, Virtanen R, Hautier Y (2020) Resource-enhancing global changes drive a wholeecosystem shift to faster cycling but decrease diversity. Ecology (online early)

Eskelinen A, Elwood E, Harrison S, Beyen E, Gremer JR (2021) Vulnerability of grassland seed banks to resource-enhancing global changes. Ecology (accepted)
Fargione J, Tilman D (2002) Competition and coexistence in terrestrial plants. competition and coexistence. Springer, Berlin, pp 165-206

Gravuer K, Eskelinen A (2017) Nutrient and rainfall additions shift phylogenetically estimated traits of soil microbial communities. Front Microbiol 8:109. https://doi.org/10.3389/fmicb.2017.01271

Harpole WS, Sullivan LL, Lind EM, Firn J, Adler PB, Borer ET et al (2016) Addition of multiple limiting resources reduces grassland diversity. Nature 537:93-96. https://doi.org/10.1038/nature19324

Harrison S, LaForgia M (2019) Seedling traits predict droughtinduced mortality linked to diversity loss. PNAS 92:201818543201825581. https://doi.org/10.1073/pnas.1818543116

Hautier Y, Niklaus PA, Hector A (2009) Competition for light causes plant biodiversity loss after eutrophication. Science 324:636-638. https://doi.org/10.1126/science.1169640

Helsen K, Ceulemans T, Stevens CJ, Honnay O (2014) Increasing soil nutrient loads of european semi-natural grasslands strongly alter plant functional diversity independently of species loss. Ecosystems 17:169-181. https://doi.org/10.1007/s10021-013-9714-8

Henry M, Stevens H, Bunker DE, Schnitzer SA, Carson WP (2004) Establishment limitation reduces species recruitment and species richness as soil resources rise. J Ecol 92:339-347. https://doi.org/ 10.1111/j.0022-0477.2004.00866.x

Högberg MN, Yarwood SA, Myrold DD (2014) Fungal but not bacterial soil communities recover after termination of decadal nitrogen additions to boreal forest. Soil Biol Biochem 72:35-43. https:// doi.org/10.1016/j.soilbio.2014.01.014

Isbell F, Tilman D, Polasky S, Binder S, Hawthorne P (2013) Low biodiversity state persists two decades after cessation of nutrient enrichment. Ecol Lett 16:454-460. https://doi.org/10.1111/ ele. 12066

Jonasson S (1988) Evaluation of the point intercept method for the estimation of plant biomass. Oikos 52:101. https://doi.org/10. 2307/3565988

Jurasinski G, Retzer V (2012) Simba: a collection of functions for similarity analysis of vegetation data. In: https://CRAN.R-proje ct.org/package $=$ cowplot. https://cran.r-project.org/web/packages/ simba/index.html. Accessed 27 Mar 2020

Kaarlejärvi E, Eskelinen A, Olofsson J (2017) Herbivores rescue diversity in warming tundra by modulating trait-dependent species losses and gains. Nat Commun 8:1-8. https://doi.org/10.1038/ s41467-017-00554-Z

Kidd J, Manning P, Simkin J, Peacock S, Stockdale E (2017) Impacts of 120 years of fertilizer addition on a temperate grassland ecosystem. PLoS One 12:e0174632. https://doi.org/10.1371/journal. pone. 0174632

Kimball S, Funk JL, Spasojevic MJ, Suding KN, Parker S, Goulden ML (2016) Can functional traits predict plant community response to global change? Ecosphere. https://doi.org/10.1002/ecs2.1602

Kitajima K, Tilman D (1996) Seed banks and seedling establishment on an experimental productivity gradient. Oikos 76:381. https:// doi.org/10.2307/3546210

Laland K, Matthews B, Feldman MW (2016) An introduction to niche construction theory. Evol Ecol 30(2):191-202

La Pierre KJ, Smith MD (2015) Functional trait expression of grassland species shift with short- and long-term nutrient additions. Plant Ecol 216:307-318. https://doi.org/10.1007/s11258-014-0438-4

Lamb EG (2008) Direct and indirect control of grassland community structure by litter, resources, and biomass. Ecology 89:216-225. https://doi.org/10.1890/07-0393.1

McGill BJ, Enquist BJ, Weiher E, Westoby M (2006) Rebuilding community ecology from functional traits. Trends Ecol Evol 21:178185. https://doi.org/10.1016/j.tree.2006.02.002

Nielsen R, Hoff A, Waldo S, Hammarlund C, Virtanen J (2019) Fishing for nutrients - economic effects of fisheries management targeting eutrophication in the Baltic Sea. Ecol Econ 160:156-167. https:// doi.org/10.1016/j.ecolecon.2019.02.013 
Olff H, Bakker JP (1991) Long-term dynamics of standing crop and species composition after the cessation of fertilizer application to mown grassland. J Appl Ecol 28:1040. https://doi.org/10.2307/ 2404224

Olsen SL, Klanderud K (2014) Exclusion of herbivores slows down recovery after experimental warming and nutrient addition in an alpine plant community. J Ecol 102:1129-1137. https://doi.org/ $10.1111 / 1365-2745.12292$

Payne RJ, Dise NB, Field CD, Dore AJ, Caporn SJ, Stevens CJ (2017) Nitrogen deposition and plant biodiversity: past, present, and future. Front Ecol Environ 15:431-436. https://doi.org/10.1002/ fee. 1528

Power SA, Green ER, Barker CG, Bell JNB, Ashmore MR (2006) Ecosystem recovery: heathland response to a reduction in nitrogen deposition. Glob Change Biol 12:1241-1252. https://doi.org/10. 1111/j.1365-2486.2006.01161.x

R Core Team (2019) R: a language and environment for statistical computing. https://www.R-project.org/. Accessed June 2019

Rasband WS (1997) ImageJ. http://rsb.info.nih.gov/ij/. Accessed Mar 2019

Reich PB (2014) The world-wide "fast-slow" plant economics spectrum: a traits manifesto. J Ecol 102:275-301. https://doi.org/10. $1111 / 1365-2745.12211$

Shaver GR, Chapin FS III (1980) Response to fertilization by various plant growth forms in an Alaskan tundra: nutrient accumulation and growth. Ecology 61:662-675

Smolders AJP, Lucassen ECHET, Van Der Aalst M, Lamers LPM, Roelofs JGM (2008) Decreasing the abundance of Juncus effusus on former agricultural lands with noncalcareous sandy soils: possible effects of liming and soil removal. Restor Ecol 16:240-248. https://doi.org/10.1111/j.1526-100X.2007.00267.x

Stark S, Eskelinen A, Männistö MK (2012) Regulation of microbial community composition and activity by soil nutrient availability, soil $\mathrm{pH}$, and herbivory in the tundra. Ecosystems 14(10):18-33

Stevens CJ (2016) How long do ecosystems take to recover from atmospheric nitrogen deposition? Biol Conserv 200:160-167. https:// doi.org/10.1016/j.biocon.2016.06.005

Stevens CJ, Duprè C, Gaudnik C, Dorland E, Dise N, Gowing D et al (2011) Changes in species composition of European acid grasslands observed along a gradient of nitrogen deposition. J Veg Sci 22:207-215. https://doi.org/10.1111/j.1654-1103.2010.01254.x

Storkey J, Macdonald AJ, Poulton PR et al (2015) Grassland biodiversity bounces back from long-term nitrogen addition. Nature 528:401-404. https://doi.org/10.1038/nature16444

Street LE, Burns NR, Woodin SJ (2015) Slow recovery of High Arctic heath communities from nitrogen enrichment. New Phytol 206:682-695. https://doi.org/10.1111/nph.13265
Strengbom J, Nordin A, Näsholm T, Ericson L (2001) Slow recovery of boreal forest ecosystem following decreased nitrogen input. Funct Ecol 15:451-457. https://doi.org/10.1046/j.0269-8463. 2001.00538.x

Suding KN, Collins SL, Gough L, Clark C, Cleland EE, Gross KL et al (2005) Functional- and abundance-based mechanisms explain diversity loss due to $\mathrm{N}$ fertilization. PNAS 102:4387-4392. https://doi.org/10.1073/pnas.0408648102

Suding KN, Lavorel S, Chapin FS, Cornelissen JHC, Díaz S, Garnier E et al (2008) Scaling environmental change through the community-level: a trait-based response-and-effect framework for plants. Glob Change Biol 14:1125-1140. https://doi.org/10.1111/j.13652486.2008.01557.x

Thakur MP, Wright AJ (2017) Environmental filtering, niche construction, and trait variability: the missing discussion. Trends Ecol Evol 32:884-886

Tilman D (1988) Plant strategies and the dynamics and structure of plant communities. Princeton University Press

Virtanen R, Grytnes JA, Lenoir J, Luoto M, Oksanen J, Oksanen L, Svenning JC (2013) Productivity-diversity patterns in arctic tundra vegetation. Ecography 36(3):331-341

Virtanen R, Clark AT, den Herder M, Roininen H (2021) Dynamic effects of insect herbivory and climate on tundra shrub growth: roles of browsing and ramet age. J Ecol 109:1250-1262. https:// doi.org/10.1111/1365-2745.13551

Wardle DA, Bardgett RD, Klironomos JN, Setätä H, van der Putten WH, Wall DH (2004) Ecological linkages between aboveground and belowground biota. Science 304:1629-1633. https://doi.org/ $10.1126 /$ science. 1094875

Welling P, Fennici KL (2000) Characteristics of the seedling flora in alpine vegetation, subarctic Finland, I. Seedling densities in 15 plant communities. Ann Bot Fenn 37:69-76. https://doi.org/10. 2307/23726937

Westoby M, Falster DS, Moles AT et al (2003) Plant ecological strategies: some leading dimensions of variation between species. Annu Rev Ecol Syst 33:125-159. https://doi.org/10.1146/annurev.ecols ys.33.010802.150452

Wickham H (2011) The split-apply-combine strategy for data analysis. J Stat Softw 40:1-29. https://doi.org/10.18637/jss.v040.i01

Wickham H (2016) ggplot2: Elegant graphics for data analysis. Springer International Publishing, New York

Wickham H (2017) Tidyverse: easily install and load the 'tidyverse'. https://tidyverse.tidyverse.org. Accessed June 2019

Wilke CO (2019) cowplot: streamlined plot theme and plot annotations for "ggplot2." In: https://CRAN.R-project.org/package= cowplot. https://cran.r-project.org/web/packages/cowplot/index. html. Accessed 27 Mar 2020 